\title{
Trust and Other Factors that Drive Students' Self-Disclosure on Social Networking Sites (SNSs)
}

\author{
LIM SOK FERN \& SITI ZANARIAH AHMAD ISHAK*
}

\author{
Faculty of Social Sciences and Humanities, Univesiti Malaysia Sarawak, 94300 Kota Samarahan, Sarawak, \\ Malaysia \\ *Corresponding author: aizana@unimas.my
}

\begin{abstract}
The aim of this study is to examine the factors that drive students' self-disclosure on Social Networking Sites (SNSs). A total of 215 undergraduates from two public universities in East Malaysia were recruited as respondents. This study adapts self-disclosure model by Elmi, A.Iahad and Ahmed (2012), where the model proposed trust as one of the factors that complementing other existing factors in online self-disclosure. This study proved that privacy concerns $(r=-.212, \mathrm{p}<.01)$, perceived trust $(\mathrm{r}=.22, \mathrm{p}<.01)$, perceived ease of use $(\mathrm{r}=.213, \mathrm{p}<.01)$, and perceived enjoyment $(\mathrm{r}=.28, \mathrm{p}<.01)$ are significantly related to students' online self-disclosure on SNSs. In addition, as trust plays a vital role in moderating the users' online self-disclosure behavior, this study formulated students' trusts on SNSs based on three dimensions which are individual, institutional and online trust. Findings of study suggested that there is a significant difference between online trust based on male and female respondents.
\end{abstract}

Keywords: Formulation of trust, online self-disclosure, privacy concern, perceived ease of use, perceived enjoyment, perceived trust

Copyright: This is an open access article distributed under the terms of the CC-BY-NC-SA (Creative Commons Attribution Non Commercial Share Alike 4.0 International License) which permits unrestricted use, distribution, and reproduction in any medium, for non-commercial purposes, provided the original work of the author(s) is properly cited.

\section{INTRODUCTION}

Many young adults in the digital era nurture their relationships with others simultaneously by virtual and face-toface interaction. In a virtual way, young adults use Social Networking Sites (SNSs) to communicate, interact and share information with others. SNSs usage shows the fastest growing and highest popularity among students in higher learning institutions across the globe (Sampasa-Kanyinga \& Lewis, 2015). Students are accustomed to share personal information such as name, picture, family members, interest, as well as personal opinion, feelings and values. Moreover, they also share everyday activities that record mundane details of daily life via SNSs. The platform allows young adult to reveal information about themselves, as well as seeking others' information via SNSs although the degree of SNSs usage are varied depending on the users. The availability of the online platform is one of the examples of factor that motivate students to reveal personal information.

Self-disclosure is defined as "an interaction between at least two individuals where at least one intends to deliberately divulge something personal to another" (Greene, Derlega, \& Mathews, 2006, p. 411). Typically, selfdisclosure is a reciprocal action where individuals are more prefer to reveal themselves to those who are more likely to disclose to them. Based on Liu and Brown (2014), participation on SNS enable users to initiate or maintain meaningful social capital bonding with others. Furthermore, the study mentioned the higher level of positive feedback received from friends on SNS predicted a closer bond and it able to enhance students' level of confidence that there are people whom can count for deeper support.

However, online self-disclosure may bring negative implications to the individual who reveal an information since SNSs is open to wider public, associates and friends. Someone may use the information to backfire the revealer. In addition, in Malaysia, the increase cases of many types of scams that involve money such as love scam is alarming (Kumar, 2018). Therefore, Blanchard, Welbourne and Boughton (2011) stated that the practice of the online disclosure behavior is linked to trust. Trust motivates the continuous engagement of online community to the virtual world (Blanchard et al., 2011). Blanchard et al. (2011) pointed that users may not fully attend to the online world and withhold the disclosure of personal information and experiences to their online friends if there is lacking of trust. 
Hence, this study aims to examine factors that influence self-disclosure on social networking sites among students in selected East Malaysia public universities in Malaysia, by adapting the self-disclosure model proposed by Elmi, A.Iahad and Ahmed (2012). The study also determines the relationship of trust with self-disclosure among female and male users on social networking sites. The model proposed is extended from the Technological Acceptance Model (Davis, 1989).

\section{Technology Acceptance Model (TAM)}

What make an individual disclose personal information via online? Technology Acceptance Model (TAM) by Fred Davis in 1989 has been adopted by past researchers to examine the question although the model is widely used to examined factors in using technological tools to communicate. It is a well-known model that explains and predicts users' acceptance of information technology. The structure of TAM included subjective norm, selfefficacy, system accessibility, perceived ease of use, perceived usefulness, attitude, and behavioral intention (Park, 2009). In the context of relationship, the factors stated are not sufficient (Elmi, A.Iahad and Ahmed 2012). Trust is in fact is an important factor in any relationship to grow.

Perceived usefulness and perceived ease of use of TAM are two important determinants to define the user's attitude and usage of a system. On the one hand, perceived usefulness is known as the degree of an individual's beliefs that there will be improvement of his or her job performance by using a particular system (Davis, 1989). Shen (2015) stated that perceived usefulness positively affects users' attitude and intention to use SNSs. For instance, social network users may believe that they are able to reduce life dissatisfaction and received social support from virtual friends when using an SNS. Not limited to perceived usefulness, the feeling of loneliness also drives people to do self-disclosure on SNSs to seek for supports and comfort (Shen, 2015).

On the other hand, Davis (1989) defined perceived ease of use is the degree of an individual's beliefs about minimum effort to be needed when using a particular system. The free of efforts motivate social network users participate in making use of the application on a site such as learn features, send stickers, post status, upload photo or other social network related activities.

\section{Formation of Trust on Social Networking Sites (SNSs)}

Trust is defined as "a belief or expectation about the other (trusted) party or as a behavioral intention or willingness to depend or rely on another party, coupled with a sense of vulnerability or risk if trust is violated" (GrabnerKrauter \& Bitter, 2015, p. 51). The formation of online trust serves to mitigate the perception of vulnerability and uncertainty that are linked with the online information disclosure.

Mesch (2012) identified three dimensions of trust in relevant to online self-disclosure, which are trust in individuals, trust in institutions and online trust. Past and present experiences of an individual are recognized as the main foundation for trust in individual (Mesch, 2012). Mesch (2012) also further discussed trust in institution is based on public knowledge and opinion about the entity's performance and reputation. Last but not least, online trust is one type of trusts that develops from online environments attributes (Mesch, 2012).

\section{The Self-Disclosure Model}

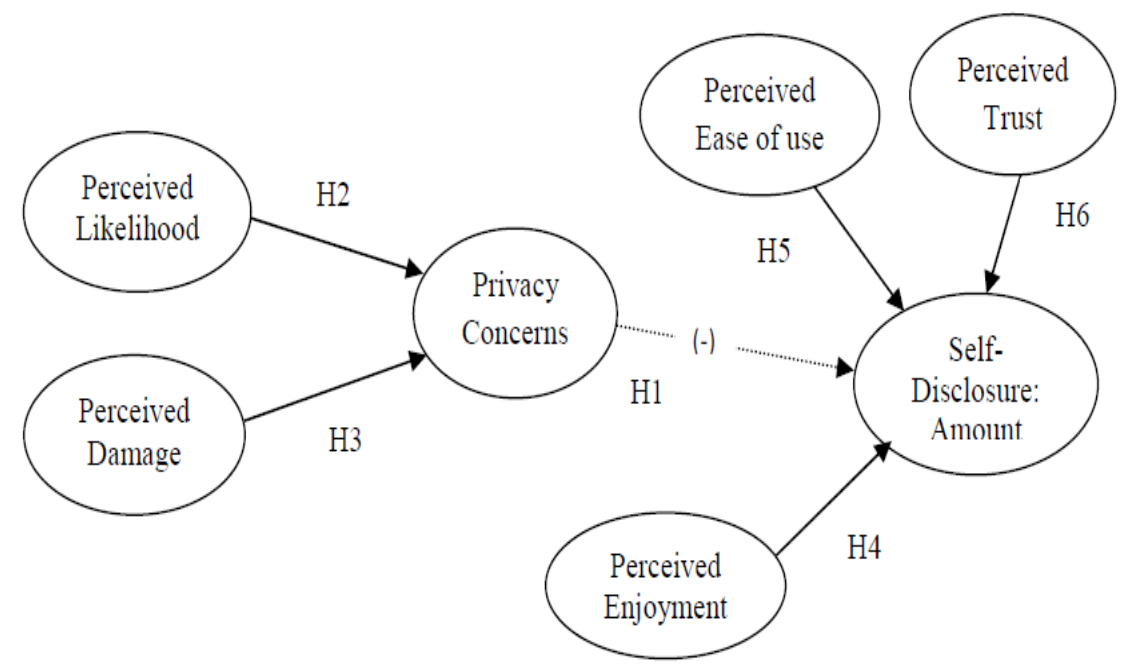

Figure 1. The proposed conceptual self-disclosure model by Elmi, A.Iahad and Ahmed (2012). 
Elmi, A.Iahad and Ahmed (2012), proposed a self-disclosure model which addressed the factors that influence the amount of online self-disclosure. The proposed conceptual model consists six hypotheses in order to generate a better understanding to the revelation issues and online self-disclosure. In the proposed framework, perceived ease of use, perceived enjoyment and perceived trust are highlighted as the factors that positively related to the online self-disclosure amount. Perceived likelihood and perceived damage are the two factors that fall under privacy concerns and labelled as the online self-disclosure inhibitors or negatively related to the online self-disclosure amount.

\section{Model and Hypotheses}

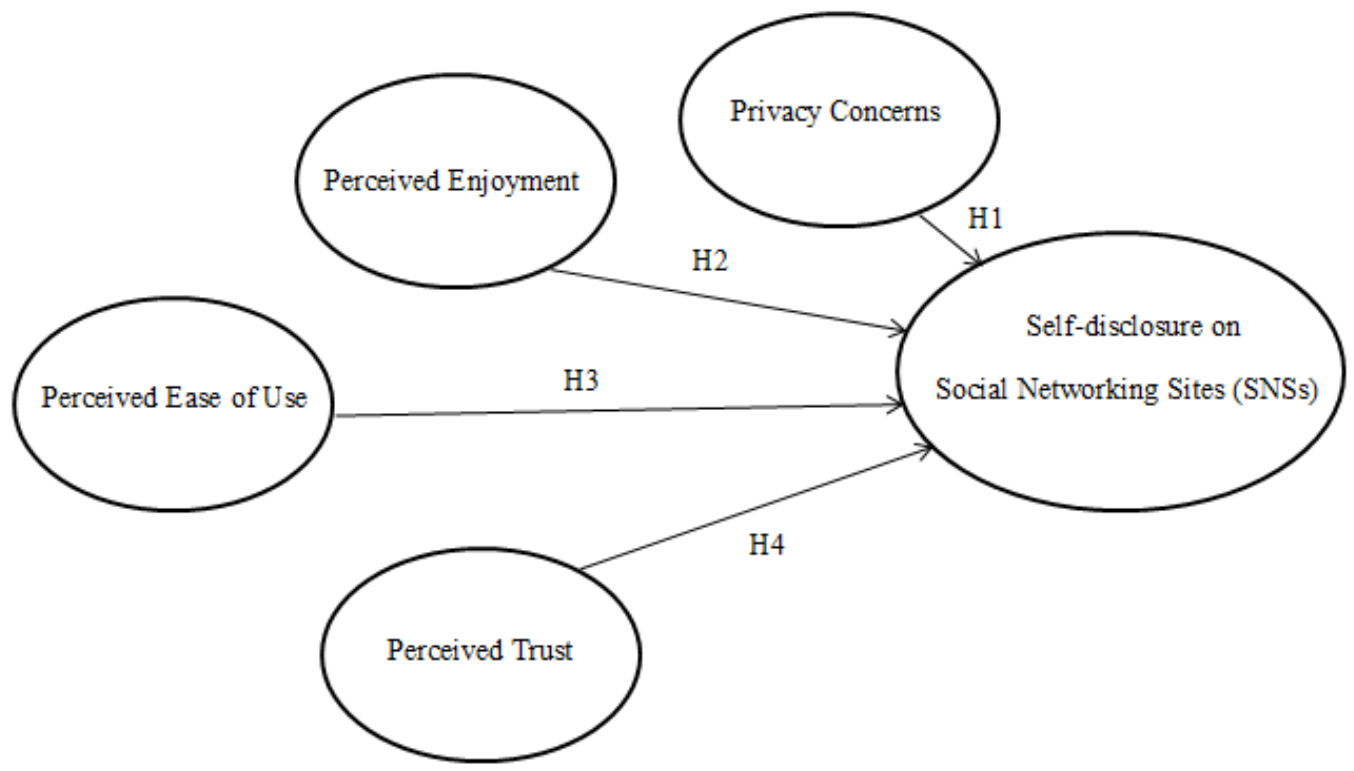

Figure 2. The conceptual framework of this research.

However, this study aimed to focus on the four main factors that closely related to online self-disclosure. A followup study is constructed based on the existing knowledge in the research area. By examining the four variables, this study aims to explain the social reality of student's online self-disclosure.

\section{Privacy concerns}

Strong concern for the protection of privacy information aids SNSs users in controlling the amount of disclosure on SNSs (Masur \& Scharkow, 2016). "Visibility" is a pivotal element in term of various levels of privacy controls. Almost all the SNSs permit default visibility level of user's profile (Tufekci, 2008). For example, people can restrict their personal profile to "public" or "friend only", users are able to control the accessibility of others to their personal information that being exposed. Students do manage the boundary between privacy and publicity (Tufekci, 2008). Tufekci (2008) proved that students limit their profiles to "friends only" on Facebook, they would concern about unwanted audiences in general thus walled off their profile. They attempt to maximize their privacy while restricting the visibility of their profiles to "friends" only. Hence, this study hypothesizes that

\section{Research Hypothesis 1: There is a significant relationship between privacy concerns and self-disclosure on social networking sites.}

\section{Perceived enjoyment}

TAM describes perceived enjoyment brings reveal of information among SNSs users. According to Rosen and Sherman (as cited in Krasnova, Kolesnikova, \& Guenther, 2009), perceived usefulness is substituted by perceived 
enjoyment claiming that SNSs acts as a hedonic information system with enjoyment composing their primary value. Past studies were focused on enjoyment as the central benefit although recognized the numerous gratifications provide by SNSs. Also, Hui, Tan, and Goh (2006) pointed out experiencing enjoyment able to justify exposure of information among users. With following previous studies, this research hypothesizes that

\section{Research Hypothesis 2: There is a significant relationship between perceived enjoyment and self-disclosure on social networking sites.}

\section{Perceived ease of use}

As mentioned by Cho (2015), people behave positively when they think a particular technology is easy to use. Users perceive SNSs to become an ideal system to carry out their duties and not to exploit user's information for personal gain. The organized information on social networking sites fulfills user's needs and allows them to quickly and easily search the information they seek. This study hypothesizes that

\section{Researcher Hypothesis 3: There is a significant relationship between perceived ease of use for self-disclosure on social networking sites.}

\section{Perceived trust}

Users are believed to the SNSs provider not to abuse their personal information. First, SNS users expect the SNSs provider will secure their private information. Secondly, they believe other members on the same site do not misuse the information they had shared. The dependency of users on social network providers aids more information to be shared with the absence of awareness. Elmi, A.Iahad and Ahmed (2012), stated lack of consciousness leads social network users failed to notice the hidden dangers of over-exposure of information and consequences that may occur. Perceived trust is associated to self-disclosure. Therefore, this study hypothesizes that

\section{Researcher Hypothesis 4: There is a significant relationship between perceived trust and self-disclosure on} social networking sites.

\section{MATERIALS \& METHODS}

Closed-ended questions are included in the self-administered questionnaire. Statistical Package for Social Sciences (SPSS) had been utilized to analyze the collected data.

\section{Measure}

This study developed a set of questionnaire with four categories. First section intended to collect respondents' demographic information, second section intended to identify information disclosure among respondent, third section aimed to examine the factors influence self-disclosure on social networking sites among respondents and last section targeted to determine the ways of formation of trust that lead to self-disclosure on social networking sites.

\section{Sample and data collection}

A total of 224 sets of questionnaires had been disseminated to the UMS and UNIMAS undergraduates. The response rate achieved $96 \%$ with a total of 215 responses were returned.

\section{RESULTS \\ Usage of SNSs}

On average, respondents had activated their social network accounts for 3.6 years and had more than 200 social networks friends. The most used social networking site was Facebook (74\%), followed by Instagram (9.8\%), Twitter (7.4\%) and other social network sites such as WeChat and WhatsApp (8.8\%). The majority (32.6\%) spent more than three hours on social networking sites daily. A total of $21.4 \%$ respondents engaged to a public displayed personal profile on SNSs, $67 \%$ respondents set their personal profile on social networking sites only viewable by only friends while 25 out of $215(11.6 \%)$ respondents limited their social networks profile to only reachable by oneself. Female users are substantially more likely than male users to have a private ("only me" and "friends only") profiles $(83.3 \%$ versus $67.7 \%$ ). By contrast, $32.3 \%$ of male respondents are more prefer than female respondents $(16.7 \%)$ to have a public profile on SNSs. 


\section{Reliability test}

In this research, the Cronbach's alpha reliability coefficient was .846 . This indicated the questionnaire had a high reliability value.

\section{Hypotheses testing}

Research Hypothesis 1 : There is a significant relationship between privacy concerns and self-disclosure on social networking sites $=$ Significant

Research Hypothesis 2 : There is a significant relationship between perceived enjoyment and self-disclosure on social networking sites $=$ Significant

Researcher Hypothesis 3 : There is a significant relationship between perceived ease of use for self-disclosure on social networking sites $=$ Significant

Researcher Hypothesis 4 : There is a significant relationship between perceived trust and self-disclosure on social networking sites $=$ Significant

This study applied the Spearman's rho Test to evaluate each individual hypothesis. As a result; H1 (Privacy concern), H2 (Perceived enjoyment), H3 (Perceived ease of use) and H4 (Perceived trust) were found to be significant in the conceptual model.

Privacy concerns $(r=-.212, \mathrm{p}<.01)$, perceived enjoyment $(\mathrm{r}=.28, \mathrm{p}<.01)$, perceived ease of use $(\mathrm{r}=.213, \mathrm{p}<$ $.01)$, perceived trust $(\mathrm{r}=.22, \mathrm{p}<0.01)$ are significantly related to student's self-disclosure behavior on SNSs. The negative of Spearman rho's correlation coefficient indicated a negative and moderate relationship between privacy concerns and self-disclosure on SNSs while the positive of Spearman rho's correlation coefficient pointed that there is a positive relationship between the two variables.

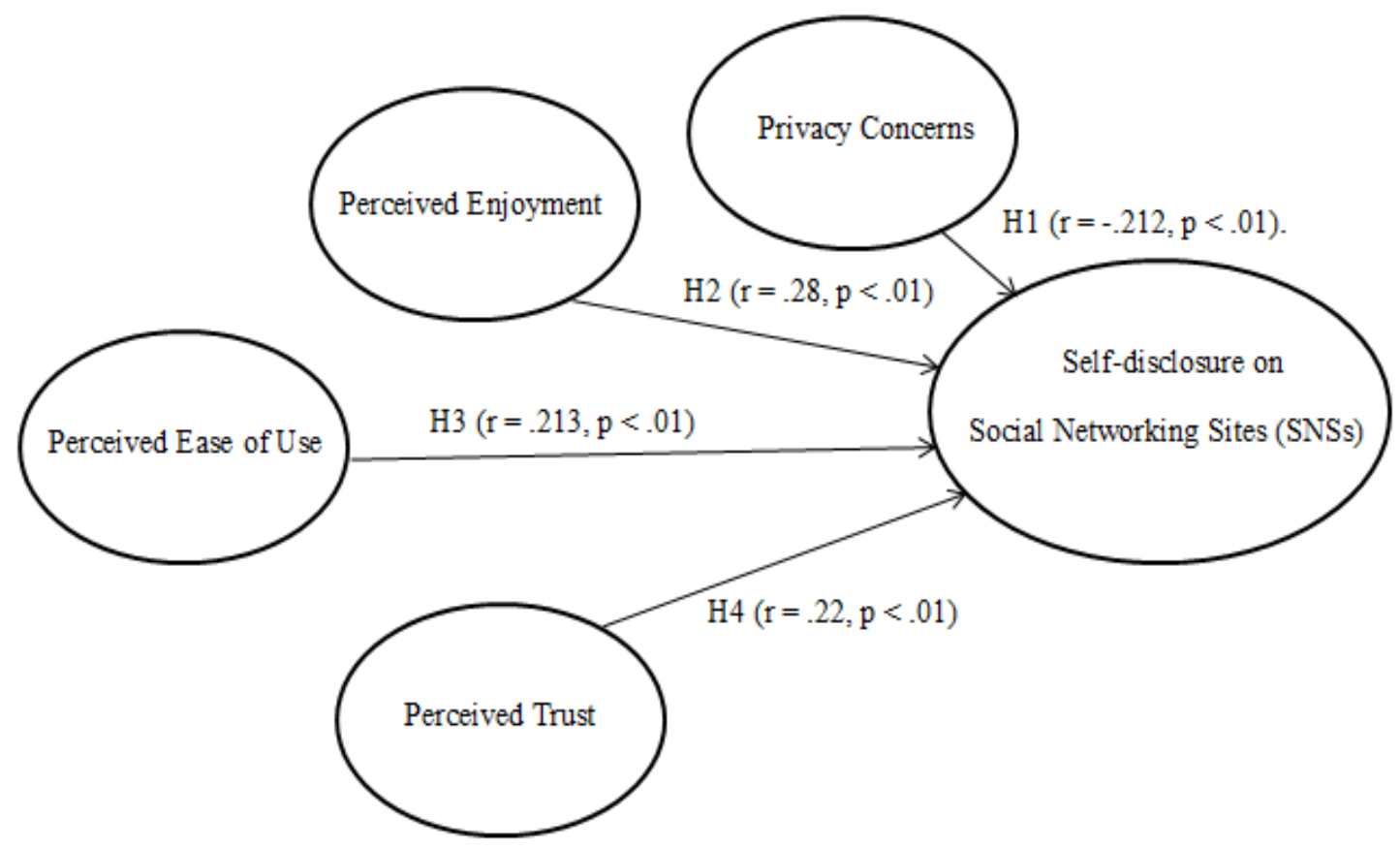

Figure 3. The result of this research. 


\section{Formation of Trust on SNSs}

The Pearson chi-square value of 10.055 at $\mathrm{p}=.001(\mathrm{p}<.05)$ shows that there is a significant difference in trust in individual between different gender. Meanwhile the chi-square test results $[\chi 2=17.735$, $\mathrm{df}=4$, at $\mathrm{p}=.001(\mathrm{p}<$ .05) demonstrates there is a significant difference in institutional trust in terms of different gender. Last but not least, for the aspect of online trust, the Pearson chi-square results $[\chi 2=14.292, \mathrm{df}=4$, at $\mathrm{p}=.006(\mathrm{p}<.05)$ pointed that there is also a significant difference between online trust based on male and female.

\section{DISCUSSION}

In general, the respondents were mostly used Facebook for more than 3 hours per day. As pointed by Mohd Khairuddin, Mohd Sallehuddin and Mohamad Fauzi Sukimi (2014), it is a necessity to have a Facebook account to connect, interact and maintain relationships with others in the digital era today. It is common for today's society that Facebook was so popular and become a daily activity. However, data in demographic information of these respondents of public universities students in East Malaysia showed that they connect more with someone they know.

Firstly, privacy concerns lead online self-disclosure. Based on the findings, the Spearman's Rho analysis concluded that privacy concern is one of the negative factors which closely related with self-disclosure on SNSs. The moderate relationship between privacy concerns and self-disclosure on SNSs in line with the respondents' online behavior where it was reported that $67 \%$ respondents set their personal profile on social networking sites only viewable by friends. As reported by Joinson, Reips, Buchanan and Schofield (2010), the privacy concerns influence users' willingness to reveal personal information on SNSs. The higher privacy concerns, the less online self-disclosure. High level of privacy concern reduced the information disclosure (McKnight, Lankton, \& Tripp, 2010).

Then, for the aspect of perceived ease of use, students admitted that the ease of use of SNSs caused them to disclose more about themselves on SNSs. With the growing popularity of SNSs, the complexity of a social network system would affects user's intention to use thus disclose about their information on the site. Lorenzo-Romero, Chiappa and Alarcon-del-Amo (2013) stated that the perceived ease of use of a system is directly associated with the online behavior. In a study conducted by Jia, Zhao and Lin (2010), perceived usefulness and perceived ease of use are closely related to user's online self-disclosure intentions and drive actual self-disclosure behavior. Social network users are more likely to be motivated and disclosed more personal information when they spend less effort with a SNS. In addition, this study also revealed that perceived enjoyment has a stronger relationship with self-disclosure on SNSs compared with other factors.

Also, perceived trust was acknowledged as one of the factors that associated with online self-disclosure. According to McKnight et al. (2010), perceived trust acts an important factor for people to exchange information with online friends. Trust which plays a vital role in moderating the users' privacy concerns and online self-disclosure behavior (Joinson et al., 2010). Also, Syed Shah Alam, Maisarah,, Khatibi and Nilurfar (2016) mentioned that trust has significantly influence users in publishing their personal information on SNSs. This study revealed that online relationship building is significantly motivated the student's self-disclosure on SNSs.

\section{CONCLUSION}

In summary, this research examines the factors that drive online self-disclosure and determines about how trust is formulated in relation to self-disclosure on SNSs. The four variables that closely related to self-disclosure on SNSs, privacy concerns, perceived ease of use, perceived trust and perceived enjoyment are empirically proved that they are significantly related to student's online self-disclosure. In line with the proposed self-disclosure model, privacy concerns are negatively related to online self-disclosure while perceived ease of use, perceived trust and perceived enjoyment are positively related to self-disclosure on SNSs. Moreover, this study contributes that users formulated their trust on SNSs based on three dimensions which are individual trust, institutional trust and online trust. Hence, it provides some vital insights for SNSs so that authorities in the society can learn the users' behavior.

\section{RECOMMENDATION}

This research contributes the knowledge about student's self-disclosure on SNSs as it was empirically tested the self-disclosure model proposed by Elmi, A.Iahad and Ahmed (2012). Not only young adult as the population of study, this research also suggests that the choice of sample be extended, for instance to middle age population of male and female and their level of education. Despite the factors that drive self-disclosure on SNSs were discussed, the breadth and depth of such disclosure were not found in order to generate a further explanation and to understand 
the online self-disclosure processes. As this study engaged in quantitative research framework, further studies should participate in qualitative research by using in-depth interview as the research method in order to reveal the breadth and depth of the online self-disclosure such as among psychologically vulnerable people.

\section{REFERENCES}

Elmi, A. Iahad, \& Ahmed (2012). Factors influence self-disclosure amount in social networking sites (SNSs). Journal of Information Systems Research and Innovation, 2, 43-50.

Blanchard, A.L., Welbourne, J.L., \& Boughton, M.D. (2011). A model of online trust. Information, Communication \& Society, 14 (1), 76- 106.

Cho, Y.C. (2015). Exploring factors that affect usefulness, ease of use, trust, and purchase intention in the online environment. International Journal of Management \& Information System, 19 (1), 21- 36.

Davis, F. D. (1989). Perceived usefulness, perceived ease of use and user acceptance of information technology. MIS Quarterly, 13 (3), 319- 340.

Grabner-Krauter, S., \& Bitter, S. (2015). Trust in online social networks: A multifaceted perspective. Forum for Social Economics 44, (1), 48- 68.

Greene, K, Derlega, V. J., \& Mathews, A. (2006). Self-disclosure in Personal Relationships. New York: Cambridge University Press.

Hui, K. L., Tan, B.C.Y., \& Goh, C. Y. (2006). Online Information Disclosure: Motivators and Measurements. ACM Transactions on Internet Technology, 6 (4), 415- 441.

Jia, Y. L., Zhao, Y., \& Lin, Y. L. (2010). Effects of system characteristics on users' self-disclosure in Social Networking Sites. IEEE Explore Digital Library, 23, 529- 533.

Joinson, A. N. (2001) Self-disclosure in computer-mediated communication: The role of self-awareness and visual anonymity. European Journal of Social Psychology, 31, 177- 192.

Joinson, A., Reips, U., Buchanan, T. \& Paine, C. B. (2010). Privacy, trust and self-disclosure online. Human Computer Interaction, 25, 1- 24.

Krasnova, H., Kolesnikova, E., \& Guenther, O. (2009). "It won’t happen to me!”: Self-disclosure in online social networks. Proceedings of the Fifteenth Americas Conference on Information Systems, California, San Francisco, pp. 1-9.

Kumar, A. (13 September 2018). Online love scams on the rise: Police. The Sun Daily. Retrieved from http://m.thesundaily.my/node/578032.

Liu, D., \& Brown, B. B. (2014). Self-disclosure on social networking sites, positive feedback, and social capital among Chinese college students. Computer in Human Behavior, 38, $213-219$.

Lorenzo-Romero C., Chiappa G. D., Alarcon-del-Amo, M. (2013). The user adoption and usage of social network sites: An empirical investigation in the context of Italy. Retrieved from http://www.marketingtrendscongress.com/archives/2013/pages/PDF/716.pdf

Masur, P. K., \& Scharkow, M. (2016). Disclosure management on social network sites: Individual privacy perceptions and user-directed privacy strategies. Social Media + Society, 2 (1), 1- 13

McKnight, D. H., Lankton, M., \& Tripp, J. (2010). Social networking information disclosure and continuance intention: A disconnect. https://www.misrc.umn.edu/workshops/2010/

Mesch, G. (2012). Is online trust and trust in social institutions associated with online disclosure of identifiable information online? Computers in HumanBehavior, 28 (4), 1471- 1477.

Mohd Khairuddin Mohd Sallehuddin \& Mohamad Fauzi Sukimi (2014) Interaksi social di ruang maya: Kajian kes jaringan social melalui laman Facebook di Malaysia. GEOGRAFIA Online ${ }^{T M}$ Malaysia Journal of Society and Space, 10 (6), 138- 147.

Park, N., Jin B., \& Jin, S. A. (2011). Effects of self-disclosure on relational intimacy in Facebook. Computers in Human Behavior, 27 (5), 1974- 1983.

Sampasa-Kanyinga, H., \& Lewis, R.F. (2015). Frequent use of social networking sites is associated with poor psychological functioning among children and adolescents. Cyberpsychology, Behavior and Social Networking, 18 (7), 380- 385.

Shen, G.C. (2015). How quality of life affects intention to use social networking sites: Moderating role of selfdisclosure. Journal of Electronic Commerce Research, 16 (4), 276- 289.

Syed Shah Alam, Maisarah Ahmad, Khatibi AA \& Nilufar Ahsan M (2016). Factors affecting trust in publishing personal information in online social network: An empirical study of Malaysia's Klang Valley users. GEOGRAFIA Online ${ }^{T M}$ Malaysia Journal of Society and Space, 12 (2), 132- 143.

Tufekci, Z. (2008) Can you see me now? Audience and disclosure regulation inonline social network sites. Bulletin of Science, Technology \& Society, 28 (1), 20- 36.

West, L., \& Turner, L. H. (2014). Introduction communication theory: Analysis and application (5 ${ }^{\text {th }}$ Edition). New York: McGraw-Hill Education. 